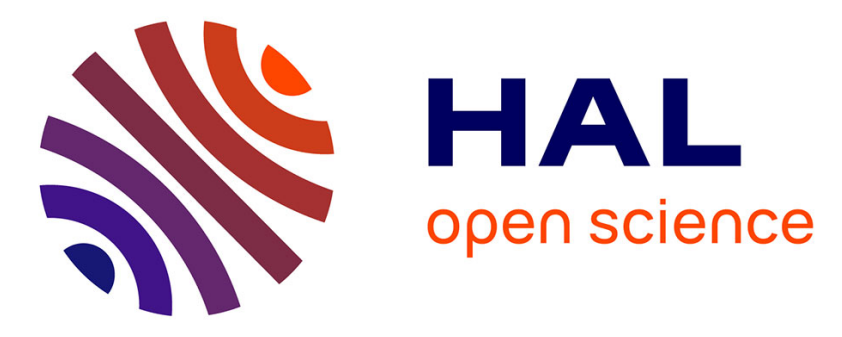

\title{
Unfolding and aggregation of lysozyme: A thermodynamic and kinetic study by FTIR spectroscopy
}

Paola Sassi, Alessandra Giugliarelli, Marco Paolantoni, Assunta Morresi, Giuseppe Onori

\section{- To cite this version:}

Paola Sassi, Alessandra Giugliarelli, Marco Paolantoni, Assunta Morresi, Giuseppe Onori. Unfolding and aggregation of lysozyme: A thermodynamic and kinetic study by FTIR spectroscopy. Biophysical Chemistry, 2011, 158 (1), pp.46. 10.1016/j.bpc.2011.05.002 . hal-00770491

\section{HAL Id: hal-00770491 https://hal.science/hal-00770491}

Submitted on 7 Jan 2013

HAL is a multi-disciplinary open access archive for the deposit and dissemination of scientific research documents, whether they are published or not. The documents may come from teaching and research institutions in France or abroad, or from public or private research centers.
L'archive ouverte pluridisciplinaire HAL, est destinée au dépôt et à la diffusion de documents scientifiques de niveau recherche, publiés ou non, émanant des établissements d'enseignement et de recherche français ou étrangers, des laboratoires publics ou privés. 


\section{Accepted Manuscript}

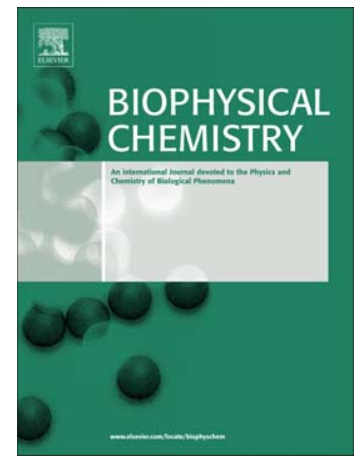

Unfolding and aggregation of lysozyme: A thermodynamic and kinetic study by FTIR spectroscopy

Paola Sassi, Alessandra Giugliarelli, Marco Paolantoni, Assunta Morresi, Giuseppe Onori

PII:

S0301-4622(11)00158-X

DOI:

doi: $10.1016 /$ j.bpc.2011.05.002

Reference:

BIOCHE 5513

To appear in: Biophysical Chemistry

Received date: 23 February 2011

Revised date: 29 April 2011

Accepted date: 1 May 2011

Please cite this article as: Paola Sassi, Alessandra Giugliarelli, Marco Paolantoni, Assunta Morresi, Giuseppe Onori, Unfolding and aggregation of lysozyme: A thermodynamic and kinetic study by FTIR spectroscopy, Biophysical Chemistry (2011), doi: 10.1016/j.bpc.2011.05.002

This is a PDF file of an unedited manuscript that has been accepted for publication. As a service to our customers we are providing this early version of the manuscript. The manuscript will undergo copyediting, typesetting, and review of the resulting proof before it is published in its final form. Please note that during the production process errors may be discovered which could affect the content, and all legal disclaimers that apply to the journal pertain. 


\title{
Unfolding and aggregation of lysozyme:
}

\section{a thermodynamic and kinetic study by FTIR spectroscopy}

\author{
$\underline{\text { Paola Sassi }}{ }^{1}$, Alessandra Giugliarelli ${ }^{1}$, Marco Paolantoni ${ }^{1}$, Assunta Morresi ${ }^{1}$, Giuseppe Onori ${ }^{2}$ \\ ${ }^{1}$ Dipartimento di Chimica, Università di Perugia, Via Elce di sotto 8, 06123 Perugia, Italy \\ 2 “Centro di Eccellenza Materiali Innovativi Nanostrutturati” (CEMIN), Università di Perugia, via \\ Elce di Sotto 10, 06123 Perugia, Italy
}

\begin{abstract}
The unfolding of hen egg-white lysozyme dissolved both in $\mathrm{D}_{2} \mathrm{O}$ and $\mathrm{CH}_{3} \mathrm{CH}_{2} \mathrm{OD} / \mathrm{D}_{2} \mathrm{O}$ was studied by Fourier Transform Infrared (FTIR) absorption spectroscopy at different protein concentrations. A detailed description of the local and global rearrangement of the secondary structure upon a temperature increase, in the range 295 to $365 \mathrm{~K}$, was obtained through the analysis of the amide I band. Thermodynamic parameters for the melting, and the effect of the co-solvent in determining a change in thermal stability of the protein were evaluated. The protein-protein interactions were also followed as a function of temperature: a strong dependence of the cluster stability and aggregation yield on the solvent composition was observed. Finally, FTIR spectra taken at successive time steps of the aggregation enabled intermolecular contacts to be monitored as a function of time, and kinetic information to be obtained showing that both unfolded and folded states of lysozyme act as reactants for the clustering event.
\end{abstract}

Keywords: lysozyme, unfolding, aggregation, FTIR, kinetics corresponding author Paola Sassi, e-mail: sassipa@ unipg.it; phone: +39 075585 5585; fax:+39 075 5855586 


\section{Introduction}

Self-assembling of polypeptide chains to form ordered structures is a general property of protein systems. It is promoted by denaturing conditions such as acidity, heating, and addition of alcohols or reducing agents[1,2]. The strong attractive interaction between protein molecules can lead to irreversible aggregation, with the formation of a stable solution of protein clusters. Association among protein side-chains can develop through a complex mechanism, from the formation of small oligomers to the creation of long fibers having a few nanometer diameter and a hundred nanometer length[3]. The study of aggregation phenomena is of great importance, owing to their well recognized implication into a number of systemic and neurodegenerative diseases[4,5]; it offers the possibility of identifying pathways able to reduce the risk of a pathological event. Also, the shell-life of foods and drugs can be sensitively extended if one of the dominant degradation routes, i.e. aggregation of proteins therein, is depleted[6,7].

The formation of ordered ensembles seems to be connected with the nature of intermolecular interactions instead of the structural properties of native monomers or their primary structure. In fact, it is well known that proteins having a different native structure may show the same tendency to produce filaments or fibrils[1,2]. Intermolecular interactions are probably induced or enhanced by the tendency to minimize the contacts with the solvent (hydrophobic effect); from this point of view an irreversible aggregation is competitive with the refolding of the single molecule.

Owing to its relatively simple structure and reduced size, hen egg white lysozyme is one of the best suited models to study protein unfolding and aggregation[8-14]. The thermal denaturation of lysozyme has been the subject of a very large number of studies, however, both aggregation and unfolding mechanisms still leaves unanswered questions; whether the solvent is able to stabilize intermediates of unfolding, and the aggregation to evolve from these species[14-16]. Lysozyme is known to form fibrils upon a rather long incubation time, at temperatures above $65^{\circ} \mathrm{C}$ and low $\mathrm{pH}$ values. These experimental conditions favor the production of multimers with a high content of $\beta$ - 
sheet structures whose stability is enhanced upon a temperature decrease (down to room temperature) [17-21].

The environment of proteins in solution may strongly influence structural motifs and, consequently, the biological function[20,21]. Intermediates of the unfolding process can lead to different pathways of aggregation, which is generally initiated by partially unfolded species $[3,7,22]$. Thus, specific solvent conditions have to be explored in order to follow the effects on the melting of single molecule on one side, and then on the intermolecular interactions on the other. In particular, adding a co-solvent to a protein solution is useful since hydrophilic and/or hydrophobic interactions between molecules can be suitably tuned[8-14,23]. Besides, specific intermediates within the mechanism of unfolding can be stabilized: a recent study on the melting process of lysozyme dissolved in water/glycerol solution, has revealed[24] the formation of a molten globule intermediate, and this has not been detected for lysozyme in water.

When using alcohol as a co-solvent, the conformational stability of the protein is a complicated function of the alcohol mole fraction $[9,10,12,13]$. At ambient temperature, the addition of small amounts of ethanol to aqueous lysozyme solution can increase the hydrophobic effect and hence lead to a compact structure ( $\alpha$-helix) of the protein [10,11]; reversely, high concentrations of alcohol favor the unfolding and aggregation of the macromolecule[11,12].

At $\mathrm{pH}=3.0$, the folded state of lysozyme is maintained at ambient temperature if the ethanol mole fraction is less than $0.25[8,9]$; as a consequence, one can follow the unfolding process upon heating the sample [14], and a deeper comprehension of reversible and irreversible denaturation processes can be achieved modulating both temperature and ethanol concentration. A detailed description of both these effects is lacking in the literature.

In the present study, we used FTIR spectroscopy to investigate unfolding and aggregation properties of lysozyme in two different media, that are $\mathrm{D}_{2} \mathrm{O}$ and the $\mathrm{D}_{2} \mathrm{O} / \mathrm{CH}_{3} \mathrm{CH}_{2} \mathrm{OD}$ mixture. Infrared absorption spectra were measured at different temperatures, in the $295-365 \mathrm{~K}$ range where both unfolding and aggregation are expected to occur. Deuterated solvents were employed to avoid 
the strong absorption of water in the mid-IR region. Relevant information about conformational changes in the structure of the protein was obtained through the analysis of amide spectral bands, without interfering signals from the solvent[25]. Unfolding and aggregation of lysozyme were revealed, and the use of two different protein concentrations enabled us to distinguish between effects of self-assembling and melting of the secondary structure. Aggregation of the protein was followed at successive time steps of the process, and kinetic parameters were determined; this allowed evidencing the conditions favorable to protein association, according to temperature and solvent composition. Moreover, the kinetic law of the nucleation event in polymer formation was obtained: this allowed evidencing the conditions favorable to protein association.

\section{Experimental Section}

\section{Materials}

Hen egg-white lysozyme (purity $\geq 90 \%$ ), $\mathrm{D}_{2} \mathrm{O}\left(99.990\right.$ atom \% D) and $\mathrm{CH}_{3} \mathrm{CH}_{2} \mathrm{OD}(99.5$ atom \% D) were purchased from Sigma-Aldrich and used without further purification.

\section{Solutions}

A solution was prepared by dissolving the lysozyme in $\mathrm{D}_{2} \mathrm{O}$ and then left to equilibrate at room temperature (generally two hours was sufficient). Full deuteration of the amide groups of the protein was achieved heating the solution up to $343 \mathrm{~K}$ and leaving it rest for 15 minutes. Cooling down the mixture, lysozyme in its native form was recovered, as evidenced by the FTIR spectrum. The solution was dissolved into additional $\mathrm{D}_{2} \mathrm{O}$ and in $\mathrm{CH}_{3} \mathrm{CH}_{2} \mathrm{OD}$ - ethanol mole fraction ( $\mathrm{x}_{\mathrm{Et}}$ ) of 0.15 and 0.18 - to obtain both compositions of $30 \mathrm{mg} / \mathrm{ml}$ (diluted samples) and $120 \mathrm{mg} / \mathrm{ml}$ (concentrated samples). A few drops of chloride acid were added to the solutions to obtain a pD of 3.0干0.1; taking account of the deuterated solvent, measured values were corrected by adding 0.4 units. pD conditions were also checked during the heating process and a few percent variation was observed in the $295-365 \mathrm{~K}$ range.

\section{FTIR spectra}


Infrared spectra were recorded using a Bruker IFS28 spectrometer equipped with a Deuterium Triglycine Sulphate (DTGS) detector. Each spectrum was the average of fifty scans, measured with a resolution of $2 \mathrm{~cm}^{-1}$. Transmission spectra were collected at various temperatures, in the 295-365 $\mathrm{K}$ range, using a specially designed cell with $\mathrm{CaF}_{2}$ windows[26]. Temperature of the experiment was controlled through a circulating water bath (Haake F6 ultra-thermostat), with a precision of $0.1 \mathrm{~K}$. Before each measurement, a 15 -minute wait was allowed to well thermalize the sample at a given selected temperature. The whole temperature scan was replicated three times on a fresh solution in order to test the reproducibility of results.

FTIR spectra were normalized to the intensity (peak area) of the amide I band in the spectrum of the $\mathrm{D}_{2} \mathrm{O}$ solution at $298 \mathrm{~K}$.

Aggregation of lysozyme at different temperatures was assessed through the evolution of the signal at $1618 \mathrm{~cm}^{-1}$ over time (nearly one hour from the beginning of the experiment), in the $\mathrm{x}_{\mathrm{Et}}=0.18$ sample: in this environment the formation of aggregates was particularly favored and the spectrum easily revealed their concentration variation. Each experiment was performed on the fresh solution thermalized at a temperature comprised in the 313-343 $\mathrm{K}$ interval. A spectrum was obtained by averaging 20 scans, each taken every 40s within the first ten minutes, and then every 120 s at longer times.

Data analysis

The position of the amide I profile in the spectrum of lysozyme, accounts for a distribution of spectral components from distinct secondary structures of the protein[27,28]. Owing to the asymmetry of such distribution, the position of the band was evaluated through the frequency first moment $\left(P_{T}\right)$ expressed as :

$$
P_{T}=\frac{\int_{b a n} \bar{v} r(\bar{v}) d \bar{\nu}}{\int_{\operatorname{ban} i} r(\bar{v}) d \bar{v}}
$$

Since $P_{T}$ is a mean vibrational frequency of oscillators involved in various secondary structures, one can refer to it as a measure of the conformational distribution of lysozyme[29]. 
It is known from the literature that the unfolding of lysozyme is properly described by a two-state model[23,30,31]. Within this model the observed spectroscopic parameter $P_{T}$ can be expressed as the value of the folded state times its population, plus the signal of the unfolded state times its population[32]:

$$
P_{T}=\frac{P_{F}+m_{F} \cdot T+\left(P_{U}+m_{Y} \cdot T\right) R_{T}}{1+R_{T}}
$$

where $K_{T}$ is the equilibrium constant at T temperature between folded and unfolded state, $F_{F}$ and $P_{U}$ denote the values of $P_{T}$ at $\mathrm{T}=0 \mathrm{~K}$ in the folded and unfolded state respectively, and $m_{F}$ and $m_{U}$ their temperature dependence. In particular, $m_{F}$ and $m_{U}$ parameters describe the linear Tdependence of the band position in the pre- and post-melting region, and this trend suggests a continuous variation for the arrangement of both folded and unfolded structures.

The equilibrium constant $K_{\mathrm{T}}$ can be expressed as a function of the unfolding enthalpy variation $\Delta H_{1 T-F}$ and of melting temperature $T_{m n}$ :

$$
\ln \left(K_{T}\right)=\frac{\Delta H_{U}-\mathrm{F}}{\mathrm{R}}\left(\frac{1}{T_{\mathrm{m}}}-\frac{1}{T}\right)
$$

We applied the non-linear least squares method of OriginPro 8 software, by OriginLab Corporation, to fit experimental values; hence, the evolution of $P_{T}$ as a function of temperature allowed thermodynamic parameters of melting of the secondary structure to be evaluated for different environments.

\section{Results and Discussion}

\section{Reversible Denaturation}

Figure 1 shows the evolution of the amide I band in the IR spectrum of a $30 \mathrm{mg} / \mathrm{ml}$ solution of lysozyme in $\mathrm{D}_{2} \mathrm{O}$ as a function of temperature, in the range 291-363K. An up-shift of the peak position along with a decrease of intensity of the amide I band is apparent through this evolution, particularly above $333 \mathrm{~K}$ (Figure $1 \mathrm{~b}$ ) due to a decrease of ordered conformations of lysozyme in the solution (from helices and sheets to turns and bends) [28]. 
Figure 2 shows plots of the first moment of the amide I band as a function of temperature for a diluted solution of lysozyme at different ethanol mole fractions: an S-shaped curve is found in all cases and reproduced according to eq.(3) (see Experimental Section). Thermodynamic parameters of the thermal unfolding were estimated and listed in Table 1 . Values of $\Delta H_{\mathrm{U}-\mathrm{F}}, T_{\mathrm{m}}$ and $\Delta S_{\mathrm{U}-\mathrm{F}}$ appear to decrease upon ethanol addition to the solution. Note that enthalpy changes and melting temperatures are in close agreement with previously reported values [8]. Our results indicate that ethanol reduces the melting temperature of the polypeptide, with a stronger effect at higher concentration . This behavior is known from the literature[8-10] but our experimental results also show the sensitivity of IR measurements to reveal the weak restructuration of conformational arrangements within the folded and unfolded states, through the evaluation of $m_{F}$ and $m_{U}$ parameters [33-35]. In fact, within the main macroscopic states of folded and unfolded forms of the molecule, some local motions can take place depending on temperature, and a progressive change of conformations can be observed upon heating. This is not in contrast with the two-state description of the unfolding process, since local rearrangements may only slightly alter the distribution of secondary structures of the protein without compromising the activity[35-37]. On the other hand, enzymes are able to perform their functions owing to some flexibility of the polypeptide chain, and this is particularly true at physiological conditions.

A comparison of $m_{F}$ and $m_{U}$ values in the three solutions (Table 1) indicates an enhanced flexibility of the polypeptide chain both in the folded and unfolded states due to the presence of ethanol, since a continuous and substantial rearrangement of the local structure is achieved for the $\mathrm{x}_{\mathrm{Et}}=0.15$ and $\mathrm{x}_{\mathrm{Et}}=0.18$ samples upon a temperature increase. For the aqueous solution, a change of slope is observed within the pre-melting region, at $T_{\mathrm{c}}=315 \mathrm{~K}$ (Figure $2 \mathrm{a}$ ), with a higher value below $T_{\mathrm{c}}$. This latter represents a kind of critical value for the aqueous solution since, at this temperature, a maximum in the free energy and hydrodynamic radius has previously been observed[38-41]. These findings seem to suggest that at $T_{\mathrm{c}}$, a local conformational transition occurs in the aqueous environment and not in the mixed solvent. In the ethanol-free sample, this conformational transition 
could be related to the temperature dependence of hydrophobic interactions; these interactions are characteristic of water, hence they are expected to be less effective in a different environment. This pre-melting transition, which has not been observed for lysozyme dissolved in other mixed solvents[24], is characteristic of lysozyme in aqueous solution. To the best of our knowledge, this is the first time that such a local effect has been evidenced by FTIR spectroscopy.

\section{Aggregation and dissociation of protein clusters}

At higher protein content, the macromolecular system may undergo a self-assembling process upon heating. In relation to the aggregation process, the presence of intermolecular $\beta$-sheet conformation can be evidenced by characteristic FTIR absorptions at 1618 and $1690 \mathrm{~cm}^{-1}[16,25]$.

FTIR spectra of the concentrated aqueous solution here investigated, lack the signature of protein clusters; in fact, the amide I band profile perfectly overlaps with that of the $30 \mathrm{mg} / \mathrm{ml} \mathrm{D}_{2} \mathrm{O}$ solution (data not shown). On the contrary, FTIR spectra of concentrated $\mathrm{D}_{2} \mathrm{O} / \mathrm{CH}_{3} \mathrm{CH}_{2} \mathrm{OD}$ solutions of lysozyme, show the presence of 1618 and $1690 \mathrm{~cm}^{-1}$ absorptions. Figure 3 displays the temperature dependence of the amide I band of a $120 \mathrm{mg} / \mathrm{ml}$ lysozyme in mixed solvent with $\mathrm{x}_{\mathrm{Et}}=0.15$. Differently from the spectra obtained at low protein concentration, one can see that the amide I profile shows the superposition of intra- and inter-molecular vibrations having different temperature evolution.

Specifically, the band at $1650 \mathrm{~cm}^{-1}$ shows a double behavior: its intensity decreases with increasing temperature in the range 310-337 K (Figure 3a), while it increases above $337 \mathrm{~K}$ (Figure 3b). This band essentially arises from $\alpha$-helix arrangements of the native structure of the protein, with minor contributions from turns (at $1670 \mathrm{~cm}^{-1}$ ). As a consequence, the decrease of intensity up to $337 \mathrm{~K}$ (indicated by a red arrow in Figure 3a) is associated with the unfolding of helix structures; on the other hand, the rise at higher temperatures (red arrow in Figure $3 b$ ) is probably due to an increase of different conformations. In fact, along with an increased intensity, the band shows a blue shift of its position, indicating a growing contribution of turn arrangements (see below). The temperature dependence of $1650 \mathrm{~cm}^{-1}$ intensity is shown in Figure 4 for both diluted and 
concentrated solutions ( blue circles in Figure 4(a) and 4(b), respectively); a loss of absorbance is observed in the 310-337 $\mathrm{K}$ range for both solutions. Hence, in analogy with the aqueous environment, the unfolding process of helix structures is likely to take place regardless of the protein concentration, at least within the range of $30-120 \mathrm{mg} / \mathrm{ml}$. However, a different conformational state is observed in concentrated solution due to the loss of helix arrangements: in fact, up to $337 \mathrm{~K}$ the position of amide I main peak red-shifts (see Figure 3a) and this is in contrast with the trend of Figure $2 b$.

The temperature dependence of $1618 \mathrm{~cm}^{-1}$ intensity is also shown in Figure 4(b) for the 120 $\mathrm{mg} / \mathrm{ml} \mathrm{sample}$. The behavior is opposite to that of the band at $1650 \mathrm{~cm}^{-1}$ : an increase up to $337 \mathrm{~K}$ is related to the formation of ordered aggregates, whilst the decrease further on suggests the rupture of these aggregates.

It is worth noting that the aggregate formation develops together with the loss of native structure of the protein (Figure 4(b)); this is also observed at higher ethanol mole fraction (see Figure 5). Concomitantly with the decrease of $\alpha$-helices, the concentration of intermolecular $\beta$ sheets increases. This indicates that the clustering process is triggered by unfolded species and develops with the fraction of those. In Figure 6, the comparison between intensity variations of $1618 \mathrm{~cm}^{-1}$ signal $\left(v_{\mathrm{AGG}}\right)$ for solutions at different ethanol content, evidences that intermolecular contacts are stable only in a limited T-interval: $333-337 \mathrm{~K}$ at $\mathrm{x}_{\mathrm{Et}}=0.15$ and $328-337 \mathrm{~K}$ at $\mathrm{x}_{\mathrm{Et}}=0.18$.,

Figure 6 also shows that the dissociation of clusters occurs at $\mathrm{T}>337 \mathrm{~K}$ for both ethanol/water solutions. Aggregate dissociation has been also observed in lysozyme under reducing conditions, in a similar temperature range[16]; in that case authors have suggested that the driving force for the dissociation of ordered assemblies is a further conformational change rather than the reversal of the aggregation process; this change coincides with the complete unfolding of lysozyme chains. Actually, we observed that the T-range of aggregate dissociation coincides with the unfolding range of lysozyme in $\mathrm{D}_{2} \mathrm{O}$ : this is also proven by the increase of absorbance at $1650 \mathrm{~cm}^{-1}$ ( Figure 4(b) and 5 ). Moreover, at $363 \mathrm{~K}$ we obtained the same unfolded state for the three 
concentrated samples, regardless the aggregation event being observed only in ternary solutions. From analysis of Figure 7 one can note that both room-temperature and high-temperature conformational states show the same secondary structure, regardless of the presence of ethanol; thermodynamic (and kinetic) effects induced by the co-solvent are observed in the temperature variations between these two situations since, in ethanol solution, a stable folded-non native state is visited by the single molecule on passing from active to open conformation.

As stated above, Figure 6 shows that the stability range of supra-molecular species increases with $\mathrm{x}_{\mathrm{Et}}$; also, the aggregation yield observed in the two ethanol solutions is different. This is probably the result of two opposite effects: the temperature-induced aggregation of monomers and the temperature-induced dissociation of aggregates. As we stated above, only the former process is solvent-dependent, and consequently a different superposition of effects is observed on heating the two ternary systems. In particular, the aggregation temperature $\left(\mathrm{T}_{\mathrm{AGG}}\right.$ in Figure 6$)$ of the $\mathrm{x}_{\mathrm{Et}}=0.18$ sample is lower than that of the $\mathrm{x}_{\mathrm{Et}}=0.15$ solution; this suggests a wider stability range for lysozyme clusters and hence the possibility of having a higher aggregation yield before the dissociation prevails.

\section{Aggregation kinetics}

Our data support the idea that heat-induced aggregation is triggered by the unfolding event and non-native monomers are involved as reactive precursors for the formation of oligomers. According to the Lumry-Eyring model[42], an irreversible and cooperative rearrangement of unfolded clusters may give rise to ordered aggregates (with a high content of $\beta$-sheet structure). This reaction constitutes the nucleation step for the polymer formation. At this stage of the mechanism, inter-chain contacts are established, as indicated by the band at $1618 \mathrm{~cm}^{-1}$ in the FTIR spectrum. We cannot exclude that this band is also sensitive to the growth of oligomers; nevertheless, it has been observed that the IR technique is almost blind to the formation of larger species (pre-fibrillar aggregates) and the spectral evolution of signals is only in the first stages of assembling[43]. 
Within the framework of this description, both unfolding and aggregation processes occur in the mechanism, with hardly separable effects. However, the intense IR absorption assigned specifically to intermolecular bonds (band $v_{\mathrm{AGG}}$ at $1618 \mathrm{~cm}^{-1}$ ) allows us to recognize and to probe the clustering event as a function of both temperature and time. Therefore, we monitored the evolution of the $v_{\mathrm{AGG}}$ intensity as a function of the time (within an hour from the beginning of the experiment) at different temperatures. In particular, we followed the growth of intermolecular $\beta$ sheets structures in the $\mathrm{x}_{\mathrm{Et}}=0.18$ solution: in this environment, the formation of aggregates is particularly favored and the spectrum can easily reveal their concentration variation.

Figure 8 displays the time evolution of $v_{A G G}$ intensity at different temperatures in the 313$343 \mathrm{~K}$ range. These data exhibit a general trend: an initial increase, within the first ten minutes of the measurement, followed by a much slower augment.

The temperature domain here explored corresponds to the melting range: for the $\mathrm{x}_{\mathrm{Et}}=0.18$ solution $T_{\mathrm{m}}=323 \mathrm{~K}$. At $T<313 \mathrm{~K}$, the band at $1618 \mathrm{~cm}^{-1}$ was not revealed: this suggests that at least a small fraction of unfolded species is required for the formation of aggregates. On the other hand, at temperatures above $343 \mathrm{~K}$, when the intra- and inter-molecular interactions are disfavored, the complete unfolding of protein sample was achieved and no evidence of aggregate formation was observed. At $T=343 \mathrm{~K}$ a sensitive decrease in the $v_{\mathrm{AGG}}$ intensity and in its variation was measured.

In Figure $8 \mathrm{~b}$, the initial aggregate formation rate $\mathrm{v}_{0}$ can be easily recognized in the slope of the different curves. It is noteworthy that this initial rate has a maximum close to the melting temperature, as shown in Figure 9. According to this finding we cannot assume that the aggregation rate is only dependent on the unfolded fraction: in this case we should observe a maximum $\mathrm{v}_{0}$ value at $\mathrm{T}=338 \mathrm{~K}$, when the total amount of protein molecules has an unfolded structure. At this temperature lysozyme experiences a maximum aggregation yield but not a maximum aggregation rate; the latter was rather obtained at $T \approx T_{\mathrm{m}}$. This could suggest that self-assembling involves both folded and unfolded species [42], and the initial rate has the following expression: 


$$
\mathrm{v}_{0}=k_{\mathrm{agg}}[\mathrm{F}]^{\mathrm{n}} \cdot[\mathrm{U}]^{\mathrm{m}}
$$

where $[\mathrm{F}]$ and $[\mathrm{U}]$ are the concentrations of the folded and unfolded states, respectively, $\mathrm{n}$ and $\mathrm{m}$ their reaction orders, and $\mathrm{k}_{\mathrm{agg}}$ is the aggregation rate constant. If we refer to the total protein concentration $[\mathrm{P}]$ and the mole fraction $\mathrm{x}_{\mathrm{F}}$ of the folded state, then we obtain:

$$
\begin{aligned}
& {[\mathrm{F}]=\mathrm{x}_{\mathrm{F}} \cdot[\mathrm{P}]} \\
& {[\mathrm{U}]=\mathrm{x}_{\mathrm{U}} \cdot[\mathrm{P}]=\left(1-\mathrm{x}_{\mathrm{F}}\right) \cdot[\mathrm{P}]} \\
& \mathrm{v}_{0}=\mathrm{k}_{\mathrm{agg}} \cdot[\mathrm{P}]^{\mathrm{n}+\mathrm{m}} \cdot \mathrm{x}_{\mathrm{F}}^{\mathrm{n}} \cdot\left(1-\mathrm{x}_{\mathrm{F}}\right)^{\mathrm{m}}
\end{aligned}
$$

In case that $\mathrm{n}=\mathrm{m}=1$, one should observe:

$$
\mathrm{v}_{0}=\mathrm{k}_{\mathrm{agg}} \cdot[\mathrm{P}]^{2} \cdot \mathrm{x}_{\mathrm{F}} \cdot\left(1-\mathrm{x}_{\mathrm{F}}\right)
$$

According to equation (6) $\mathrm{v}_{0}$ has a maximum when $\mathrm{x}_{\mathrm{F}}=0.5$, and this is verified at $\mathrm{T}=\mathrm{T}_{\mathrm{m}}$. In our data this maximum was observed at $\mathrm{x}_{\mathrm{F}}$ slightly lower than 0.5 , thus $\mathrm{m}$ is probably higher than $\mathrm{n}$; nevertheless, a more accurate study is requested to define the kinetic law precisely.

The participation of native molecules to protein self-assemblies was also proposed for lysozyme under reducing condition[44], and authors suggested a possible inclusion of folded molecules within the structure or at the surface of the clusters during the growing phase of polymerization. Our results demonstrate that together with unfolded chains, also native molecules act as reactants of the nucleation event, as expressed by the dependence of $\mathrm{v}_{0}$ on $\mathrm{x}_{\mathrm{F}}$ and $\mathrm{x}_{\mathrm{U}}$.

The gelation process

One of the most striking results of our kinetic measurements is that, within the reaction time (1h), we obtained different aggregate fractions at different temperatures, thus resembling the trend of Fig. 6 where a single sample was heated in the whole $T$ range and measurements were taken after 15-minute equilibration. The presence of such limiting concentrations is not obvious since one can imagine the irreversible self-assembling to consume the protein completely, even though at different rates. This is not the case and we obtained different samples (e.g. different cluster/monomer fractions) at different temperatures. 
We believe this to be connected with the marked increase of viscosity of the sample due to an increase in cluster concentration. In fact, we observed the formation of transparent gels with a higher strength at higher temperatures (data not shown). Heat-set gelation of globular proteins is a well known phenomenon[17-19,45], and the formation of a transparent gel is usually connected with the growth of ordered clusters[45], as revealed by our data. The formation of a gel seems to hinder the conformational rearrangements of the protein, and this may substantially reduce the rate of any further assembling.

\section{Conclusions}

In the present study, conformational changes induced by temperature on lysozyme dissolved in different environments were analyzed in relation to protein unfolding and self-assembling.

A detailed analysis of pre-melting effects was performed for different solutions; in particular, a local rearrangement of the secondary structure was evinced only for the binary system. An enhanced sensitivity of protein conformations to the temperature variation was revealed with increasing the fraction of ethanol as a co-solvent, and a reduced thermal stability of the folded state of lysozyme was evidenced from the behavior of the amide I band profile. The reduced thermal stability and the continuous rearrangement of the secondary structure suggested the presence of weakened hydrophobic interactions in the solution with ethanol. On the other hand, an enhancement of intermolecular interactions was observed upon increase of alcohol concentration.

From the comparison of data at low and high protein concentration, a clear comprehension of effects due to the unfolding on one side, and the aggregation on the other was obtained for the protein in water/ethanol solutions. The evidence of an irreversible association initiated by the unfolded state of the macromolecule was verified; nonetheless, the participation of the native state of the protein was also revealed from the temperature dependence of the initial rate of aggregate formation. 
The complete unfolding of lysozyme chains was observed as the result of aggregate dissociation. For both water/ethanol solutions this dissociation was detected at the temperatures of lysozyme melting in water $(\mathrm{T}>337 \mathrm{~K})$. On the contrary, a lower aggregation temperature was observed on increasing the ethanol content, thus: a different range of cluster stability and a different aggregation yield was evidenced in the two ternary systems.

Monitoring the aggregation process as a function of time we also observed the formation of transparent gels: we believe that the increase of viscosity connected to gelation is responsible for the decrease of aggregation rate observed at each temperature and long reaction times. Due to the "freezing" of conformational motions, we obtained different transparent gels (e.g. different cluster/monomer fractions) at different temperatures; the characterization of the systems obtained by different thermal treatments, will be the subject of our future studies. 


\section{References}

[1]: C.M. Dobson, The structural basis of protein folding and its links with human disease, Phil. Trans. Roy. Soc. London, 356 (2001) 133-146.

[2]: C.M. Dobson, Protein misfolding, evolution and disease, Trends Biochem. Sci. 24 (1999) 329332.

[3]: V.N. Uversky and A.L. Fink, Conformational constraints for amyloid fibrillation: the importance of being unfolded, Biochim. Biophys. Acta, 1698 (2004) 131-153.

[4]: S.S.S. Wang and T.A. Good, An overview of Alzheimer's disease, J. Chin. Inst. Chem. Eng. 36 (2005) 533-559

[5]: T. Yamaguchi, H. Yagi, Y. Goto, K. Matsuzaki and M. Hoshino, A Disulfide-Linked Amyloidbeta Peptide Dimer Forms a Protofibril-like Oligomer through a Distinct Pathway from Amyloid Fibril Formation, Biochemistry, 49 (2010) 7100-7107

[6]: A.M. Morris, A.W. Murielle and R.G. Finke, Protein aggregation kinetics, mechanism, and curve-fitting: A review of the literature, Biochim. Biophys. Acta 1794 (2009) 375-397.

[7]: M. Calamai, F. Chiti and C.M. Dobson, Amyloid fibril formation can proceed from different conformations of a partially unfolded protein, Biophys. J. 89 (2005) 4201-4210.

[8]: A. Bonincontro, A. De Francesco, M. Matzeu, G. Onori and A. Santucci, Conformational changes of lysozyme in water-ethanol mixtures, Colloids and surfaces B, 10 (1997) 105-111.

[9]: S. Cinelli, G. Onori and A. Santucci, Effect of 1-alcohols on micelle formation and protein folding, Colloids Surf., A160 (1999) 3-8.

[10]: W. Liu, D. Bratko, J.M. Prausnitz and H.W. Blanch, Effect of alcohols on aqueous lysozymelysozyme interactions from static light-scattering measurements, Biophys. Chem., 107 (2004) 289298.

[11]: K. Sasahara and K. Nitta, Effect of ethanol on folding of hen egg-white lysozyme under acidic condition, Proteins: Struct., Funct., Bioinf. 63 (2006) 127-135. 
[12]: P. Westh and Y. Koga, Intermolecular interactions of lysozyme and small alcohols: A calorimetric investigation, J. Phys. Chem. B 101 (1997) 5755-5758.

[13]: M.K. Goyal, I. Roy, U.C. Banerjee, V.K. Sharma and A.K., Bansal, Role of benzyl alcohol in the prevention of heat-induced aggregation and inactivation of hen egg white lysozyme, $E . J$. Pharm. Biopharm., 71 (2009) 367-376.

[14]: P. Sassi, G. Onori, A. Giugliarelli, M. Paolantoni, S. Cinelli and A. Morresi, 2011, Conformational changes in the unfolding process of lysozyme in water and ethanol/water solutions, J Mol. Liq., 159 (2011) 112-116.

[15]: A. Lerbret, F. Affouard, P. Bordat, A. Hédoux, Y. Guinet and M. Descamps, Low-frequency vibrational properties of lysozyme in sugar aqueous solutions: A Raman scattering and molecular dynamics simulation study, J. Chem. Phys. 131 (2009) 245103.

[16]: F. Meersman and K. Heremans, Temperature-induced dissociation of protein aggregates: Accessing the denatured state, Biochemistry, 42 (2003) 14234-14241.

[17]: H. Yan, A. Saiani and A.F. Miller, Gelation of a model protein, Macromol. Symp., 251 (2007) 112-117.

[18]: M.A. Silva, I.A. Farhat, E.P.G. Arêas and J.R. Mitchell, Solvent-induced lysozyme gels: effects of system composition and temperature on structural and dynamical characteristics, Biopolymers 83 (2006) 443-454.

[19]: A. Cao, D. Hu, D. and L. Lai, Formation of amyloid fibrils from fully reduced hen egg white lysozyme, Prot. Sci. 13 (2004) 319-324.

[20]: M. Tehei and G. Zaccai, Adaptation to extreme environments: macromolecular dynamics in complex systems, Biochim. Biophys. Acta , 1724 (2005) 404-410.

[21]: N. Prabhu and K. Sharp, Protein-solvent interactions, Chem. Rev. 106 (2006) 1616-1623.

[22]: F. Chiti and C.M. Dobson, Protein misfolding, functional amyloid, and human disease, Annu. Rev. Biochem. 75 (2006) 333-366 
[23]: I.L. Shulgin and E. Ruckenstein, Local composition in the vicinity of a protein molecule in an aqueous mixed solvent, J. Phys. Chem. B 111 (2007), 3990-3998.

[24]: A. Esposito, L. Comez, S. Cinelli, F. Scarponi and G. Onori, Influence of glycerol on the structure and thermal stability of lysozyme: a dynamic light scattering and circular dichroism study, J. Phys. Chem. B 113 (2009) 16420-16424.

[25]: J.S. Vrettos and C.W. Meuse, Infrared techniques for quantifying protein structural stability, Analytical Biochem. 390 (2009) 114-120.

[26]: M. Freda, A. Piluso, A. Santucci and P. Sassi, Transmittance Fourier Transform Infrared spectra of liquid water in the whole mid-infrared region: temperature dependence and structural analysis, Applied Spectroscopy 59 (2005) 1155-1159.

[27]: H.H. Mantsch and D. Chapman, Eds. Infrared spectroscopy of biomolecules: Wiley-Liss Inc.: New York, 1996.

[28]: H.U. Gremlich and B. Yan, Eds. Infrared and Raman spectroscopy of biological materials: Marcel Dekker Inc.: New York, 2001.

[29]: see for example: a)F. Eker, K. Griebenow, R. Schweitzer-Stenner, Ab1-28 fragment of the amyloid peptide predominantly adopts a polyproline II conformation in an acidic solution, Biochemistry 43 (2004) 6893-6898. b) T.J. Measey, R. Schweitzer-Stenner, Vibrational circular dichroism as a probe of fibrillogenesis: the origin of the anomalous intensity enhancement of amyloid-like fibrils, J.Am.Chem.Soc. 133 (2010) 1066-1076.

[30]:S.E. Jackson, How do small single-domain proteins fold?, Folding Des. 3 (1998) 81-91.

[31]: E.P. O’Brien, B.R. Brooks and D. Thirumalai, Molecular Origin of Constant $m$-Values, Denatured State Collapse, and Residue-Dependent Transition Midpoints in Globular Proteins, Biochemistry 48 (2009) 3743-3754.

[32]: B. Nölting, Protein folding kinetics: Biophysical Methods: Ed. Springer-Verlag, Berlin, 1999.

[33]: J.C.Q. Smith, Protein dynamics: comparison of simulations with inelastic neutron scattering experiments, Q. Rev. Biophys. 24 (1991) 227-291. 
[34]: G. Zaccai, How soft is a protein? A protein dynamics force constant measured by neutron scattering, Science 288 (2000) 1604-1607.

[35]: J. Gosline, M. Lillie, E. Carrington, P. Guerrette, C. Ortlepp and K. Savage, Elastic proteins: biological roles and mechanical properties, Phil. Trans. R. Soc. Lond. B, 357 (2002) 121-132.

[36]: S. Ciliberti, P. De Los Rios and F. Piazza, Glasslike Structure of Globular Proteins and the Boson Peak, Phys. Rev. Lett. 96 (2006) 19810.

[37]: S. Reuveni, R. Granek and J. Klafter, Proteins: coexistence of stability and flexibility, Phy. Rev. Lett. 100 (2008) 208101.

[38]: J.Y. Chang and L. Li, The unfolding mechanism and the disulfide structures of denatured lysozyme, FEBS Letters 511 (2002) 73-78.

[39]: W. Pfeil and P.L. Privalov, Thermodynamic investigations of proteins. I. Standard functions for proteins with lysozyme as an example, Biophys. Chem. 4 (1976) 23-32.

[40]: W. Pfeil and P.L. Privalov, Thermodynamic investigations of proteins. II. Calorimetric study of lysozyme denaturation by guanidine hydrochloride, Biophys. Chem. 4 (1976) 33-40.

[41]: W. Pfeil and P.L. Privalov, Thermodynamic investigations of proteins. III. Thermodynamic description of lysozyme, Biophys. Chem. 4 (1976) 41-50.

[42]: C.J. Roberts, Non-native protein aggregation kinetics, Biotechnol. Bioeng. 98 (2007) 927-938.

[43]: N. Benseny-Cases, M. Cocera and J. Cladera, Conversion of non-fibrillar $\beta$-sheet oligomers into amyloid fibrils in Alzheimer's disease amyloid peptide aggregation, Biochem. Biophys. res. Comm. 361 (2007) 916-921.

[44]: A.M. Buswell and A.P.J. Middelberg, Critical analysis of lysozyme refolding kinetics, Biotechnol. Prog. 18 (2002) 470-475.

[45]: T. Nicolai and D. Durand, Protein aggregation and gel formation studied with scattering methods and computer simulations, Curr. Opin. Colloid Interface Sci. 12 (2007) 23-28. 
Table 1. Parameter evaluated for diluted lysozyme solutions

\begin{tabular}{|c|c|c|c|c|c|}
\hline $\mathbf{x}_{\mathrm{Et}}$ & $\begin{array}{c}\Delta \mathrm{H}_{\mathrm{U}-\mathrm{F}} \\
/ \mathrm{kcal} \mathrm{mol}^{-1}\end{array}$ & $\begin{array}{l}\mathbf{T}_{\mathbf{m}} \\
/ \mathbf{K}\end{array}$ & 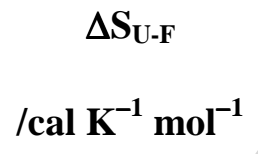 & $\begin{array}{c}m_{F} \\
/ \mathbf{K}^{-1} \mathbf{c m}^{-1}\end{array}$ & $\begin{array}{c}m_{U} \\
/ \mathbf{K}^{-1} \mathbf{c m}^{-1}\end{array}$ \\
\hline 0.00 & $116.7 \pm 6.0^{*}$ & $348.0 \pm 0.5$ & $335.3 \pm 19.0$ & $0.019 * * \pm 0.002$ & $0.021 \pm 0.002$ \\
\hline 0.15 & $95.0 \pm 9.0$ & $328.4 \pm 0.7$ & $289.3 \pm 29.0$ & $0.065 \pm 0.005$ & $0.060 \pm 0.004$ \\
\hline 0.18 & $73.0 \pm 8.0$ & $323.6 \pm 0.9$ & $225.6 \pm 28.0$ & $0.067 \pm 0.005$ & $0.060 \pm 0.003$ \\
\hline
\end{tabular}

* Uncertainties are derived from the applied fitting procedure

** Value obtained at temperatures higher than $T_{\mathrm{c}}=315 \mathrm{~K}$. 


\section{Figure captions}

Figure 1: FTIR spectrum in the region of the amide I band of a $30 \mathrm{mg} / \mathrm{ml}$ solution of hen egg-white lysozyme in $\mathrm{D}_{2} \mathrm{O}$ at different temperatures, in the 291 to $333 \mathrm{~K}$ (a), and 333 to $363 \mathrm{~K}$ (b) ranges.

Figure 2: Evolution of the first moment $P_{T}$ of the amide I band for a $30 \mathrm{mg} / \mathrm{ml}$ solution as a function of temperature. The frequency first moment was evaluated from FTIR spectra of $x_{\mathrm{Et}}=0.00$ solution (a), $\mathrm{x}_{\mathrm{Et}}=0.15$ solution (b), and $\mathrm{x}_{\mathrm{Et}}=0.18$ solution (c); black, pink and green squares refer to the three determinations performed to test the reproducibility of results on each sample. Red curves are the result of fitting procedure described by equation (2) (see text), and performed on the complete data set; blue line is only a guide for the eyes.

Figure 3: FTIR spectra of lysozyme $120 \mathrm{mg} / \mathrm{ml}$ solution in $\mathrm{D}_{2} \mathrm{O} / \mathrm{CH}_{3} \mathrm{CH}_{2} \mathrm{OD} \mathrm{x} \mathrm{x}_{\mathrm{Et}}=0.15$, in the region of the amide I absorption band.

Figure 4: IR intensity of the $1650 \mathrm{~cm}^{-1}$ band (scale on right axis) and $1618 \mathrm{~cm}^{-1}$ band (scale on left axis) measured on spectra of diluted (a) and concentrated (b) lysozyme solutions in $\mathrm{D}_{2} \mathrm{O} / \mathrm{CH}_{3} \mathrm{CH}_{2} \mathrm{OD}$-solution, $\mathrm{x}_{\mathrm{Et}}=0.15$.

Figure 5: IR intensity of the $1650 \mathrm{~cm}^{-1}$ band (scale on right axis) and $1618 \mathrm{~cm}^{-1}$ band (scale on left axis) measured on spectra of lysozyme $120 \mathrm{mg} / \mathrm{ml} \mathrm{D} 2 \mathrm{O} / \mathrm{CH}_{3} \mathrm{CH}_{2} \mathrm{OD}$-solution, $\mathrm{x}_{\mathrm{Et}}=0.18$.

Figure 6: IR intensity of the $1618 \mathrm{~cm}^{-1}$ band $\left(v_{\mathrm{AGG}}\right)$ measured on spectra of a $120 \mathrm{mg} / \mathrm{ml}$ $\mathrm{D}_{2} \mathrm{O} / \mathrm{CH}_{3} \mathrm{CH}_{2} \mathrm{OD}$-solutions: red circles $\mathrm{x}_{\mathrm{Et}}=0.15$; black squares $\mathrm{x}_{\mathrm{Et}}=0.18$. The aggregation temperature $\mathrm{T}_{\mathrm{AGG}}$ is referred to the midpoint of the intensity increase. 
Figure 7: Amide I profile for lysozyme $120 \mathrm{mg} / \mathrm{ml} \mathrm{D} 2 \mathrm{O}$-solution (black curves), $\mathrm{D}_{2} \mathrm{O} / \mathrm{CH}_{3} \mathrm{CH}_{2} \mathrm{OD}$ solution $\mathrm{x}_{\mathrm{Et}}=0.15$ (blue curves), $\mathrm{D}_{2} \mathrm{O} / \mathrm{CH}_{3} \mathrm{CH}_{2} \mathrm{OD}$-solution $\mathrm{x}_{\mathrm{Et}}=0.18$ (red curves). The superposition of curves suggests the presence of the same folded state at $298 \mathrm{~K}$, and the same unfolded state at $363 \mathrm{~K}$, for lysozyme in the three solvents.

Figure 8: Increase of IR intensity at $1618 \mathrm{~cm}^{-1}\left(v_{\mathrm{AGG}}\right)$ measured on spectra of a $120 \mathrm{mg} / \mathrm{ml}$ $\mathrm{D}_{2} \mathrm{O} / \mathrm{CH}_{3} \mathrm{CH}_{2} \mathrm{OD}$-solution $\mathrm{x}_{\mathrm{Et}}=0.18$, at different temperatures. Data shown in graph (b) refer to the first minutes of reaction and are the same of graph (a). Dashed lines are the results of a linear curvefitting applied to the initial intensity increase.

Figure 9: Initial aggregate formation rate $\mathrm{v}_{0}$ as evaluated from the slope of lines reported in Fig.8b 


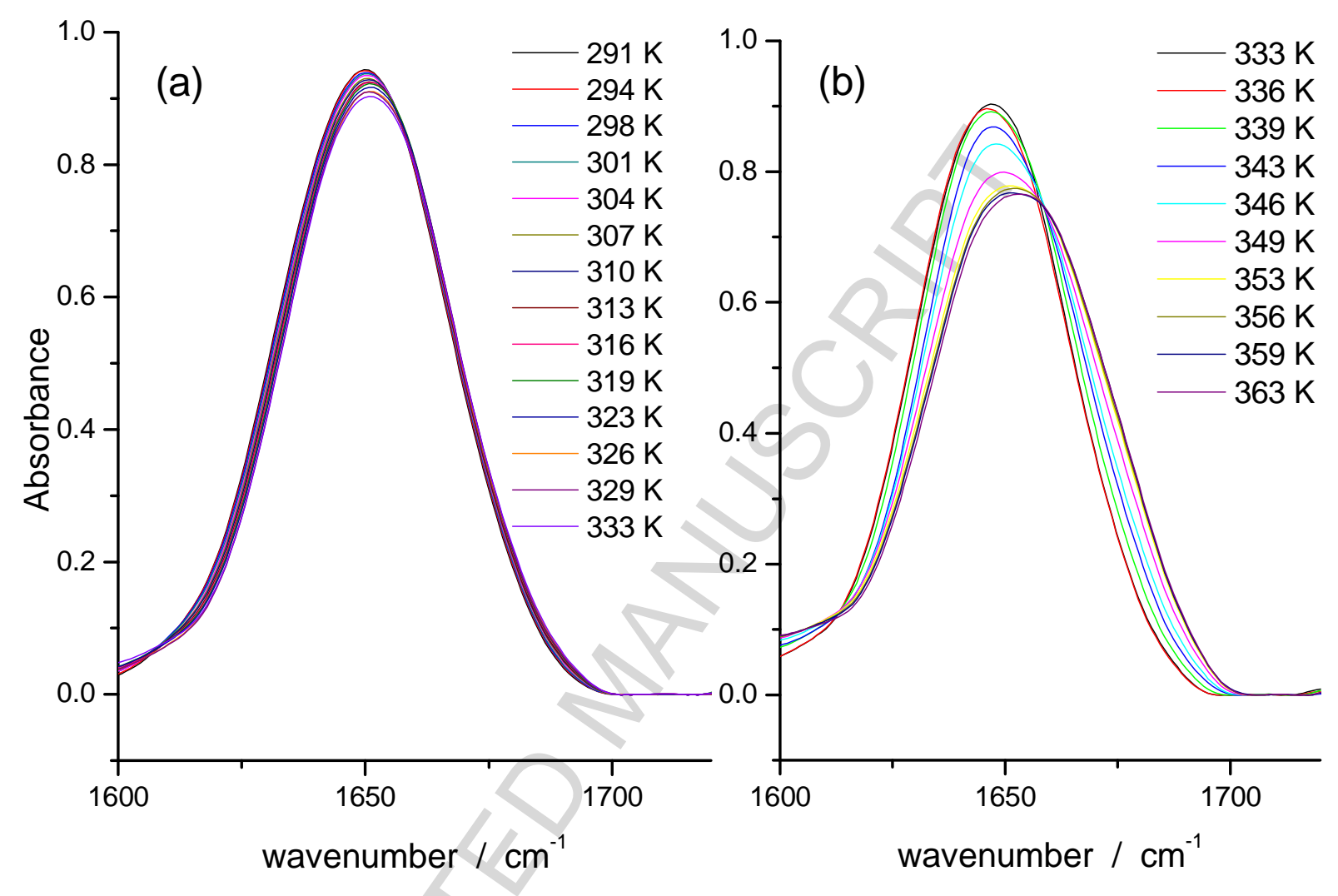

Figure 1 


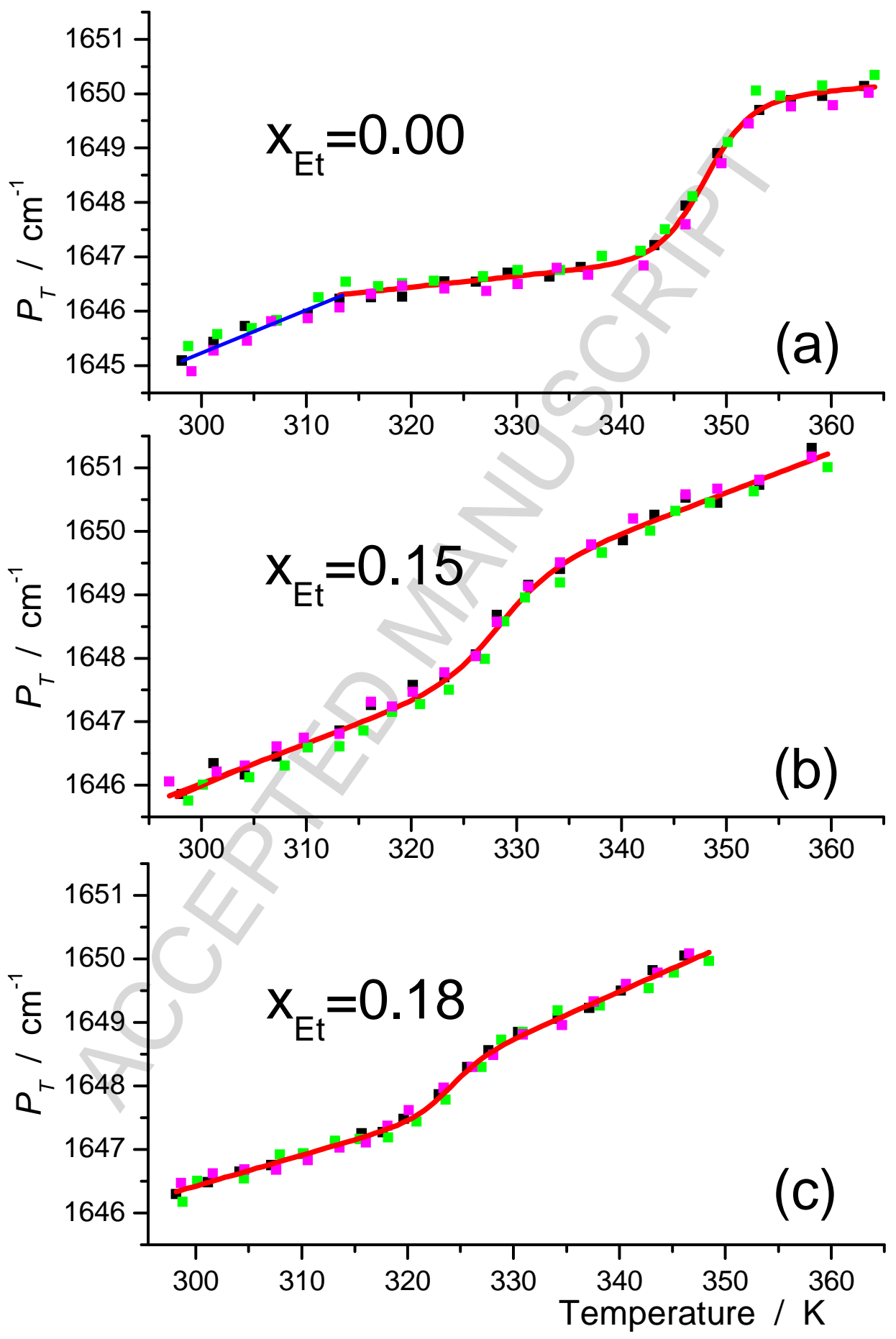

Figure 2 

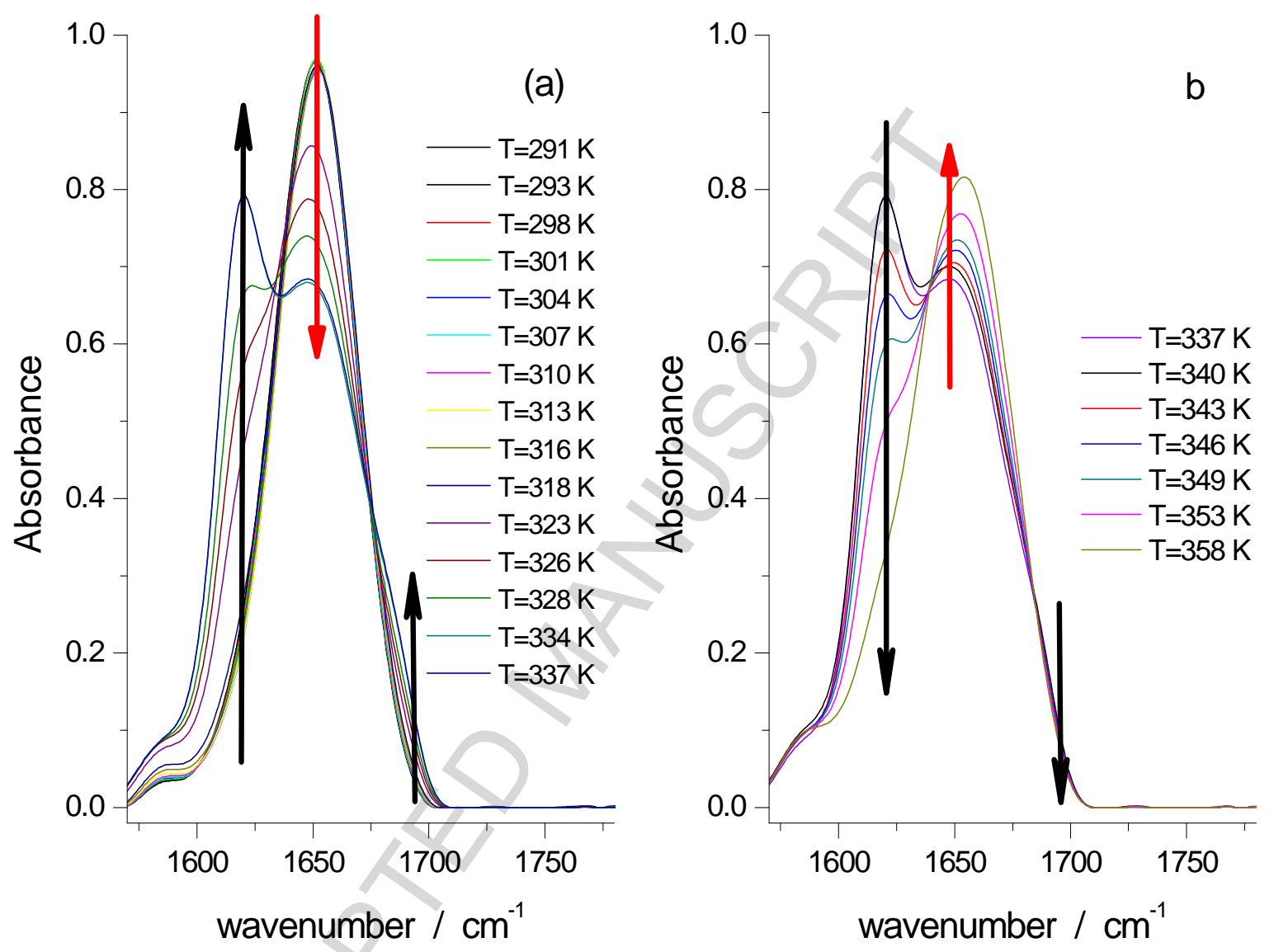

Figure 3 


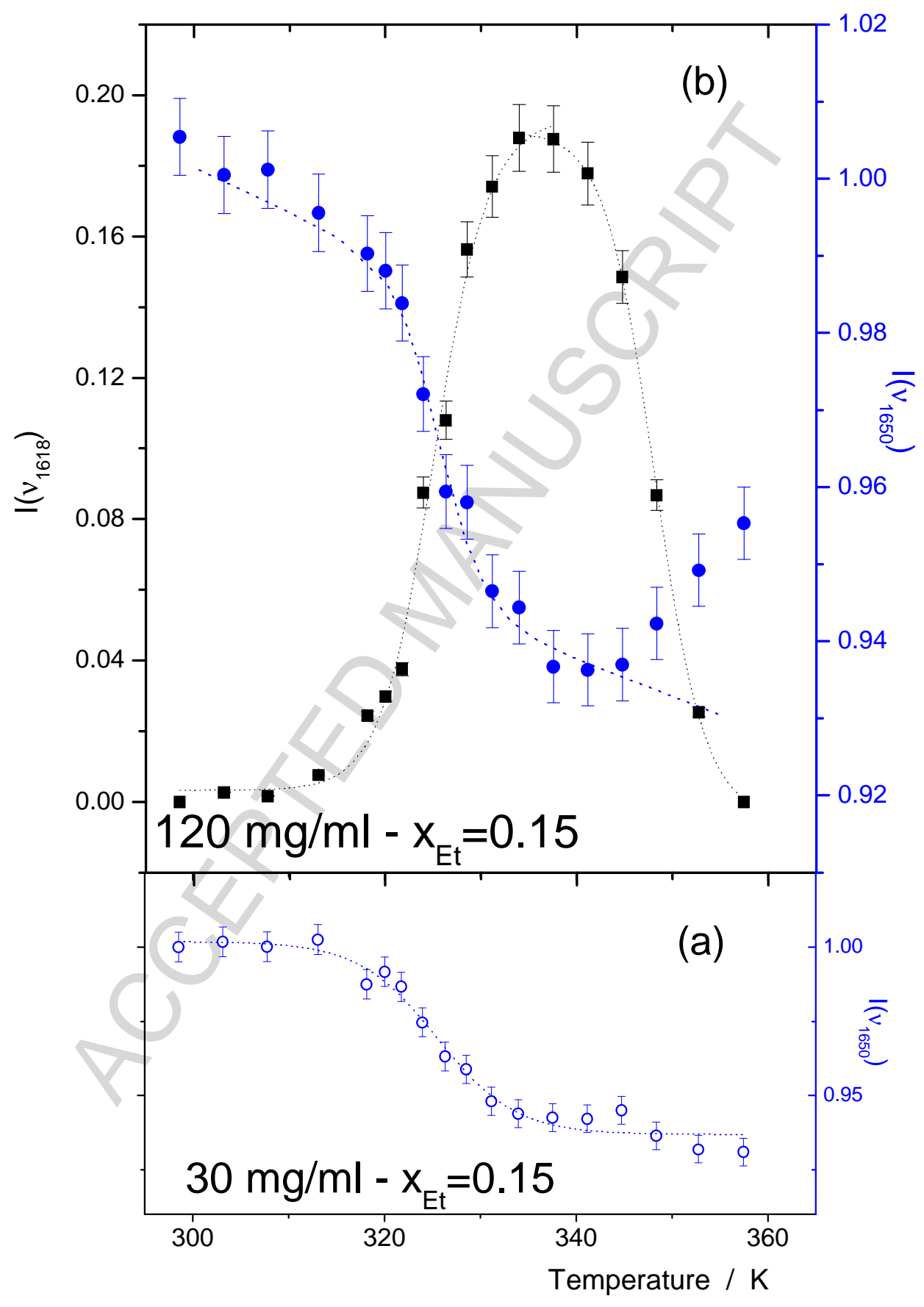

Figure 4 


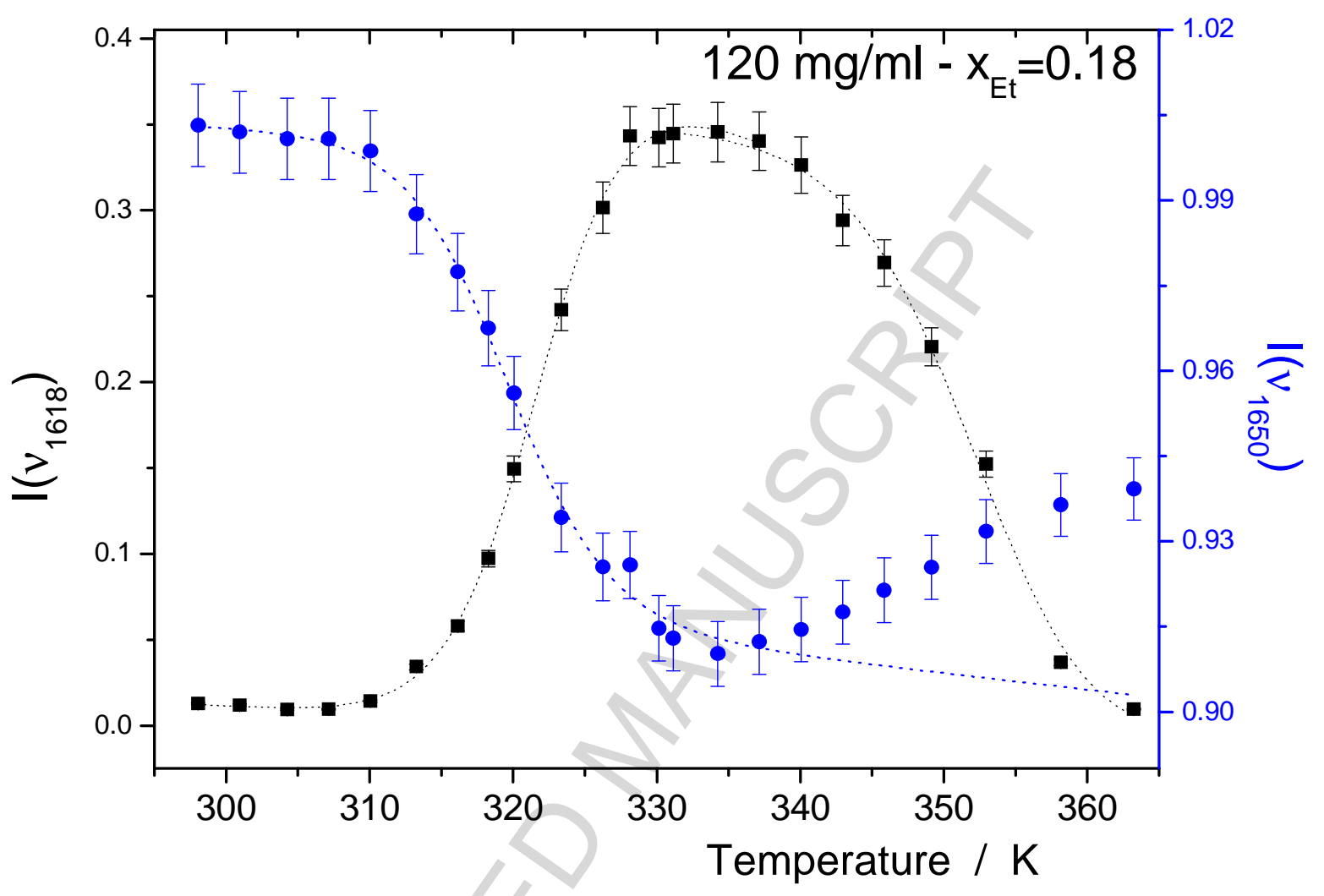

Figure 5 


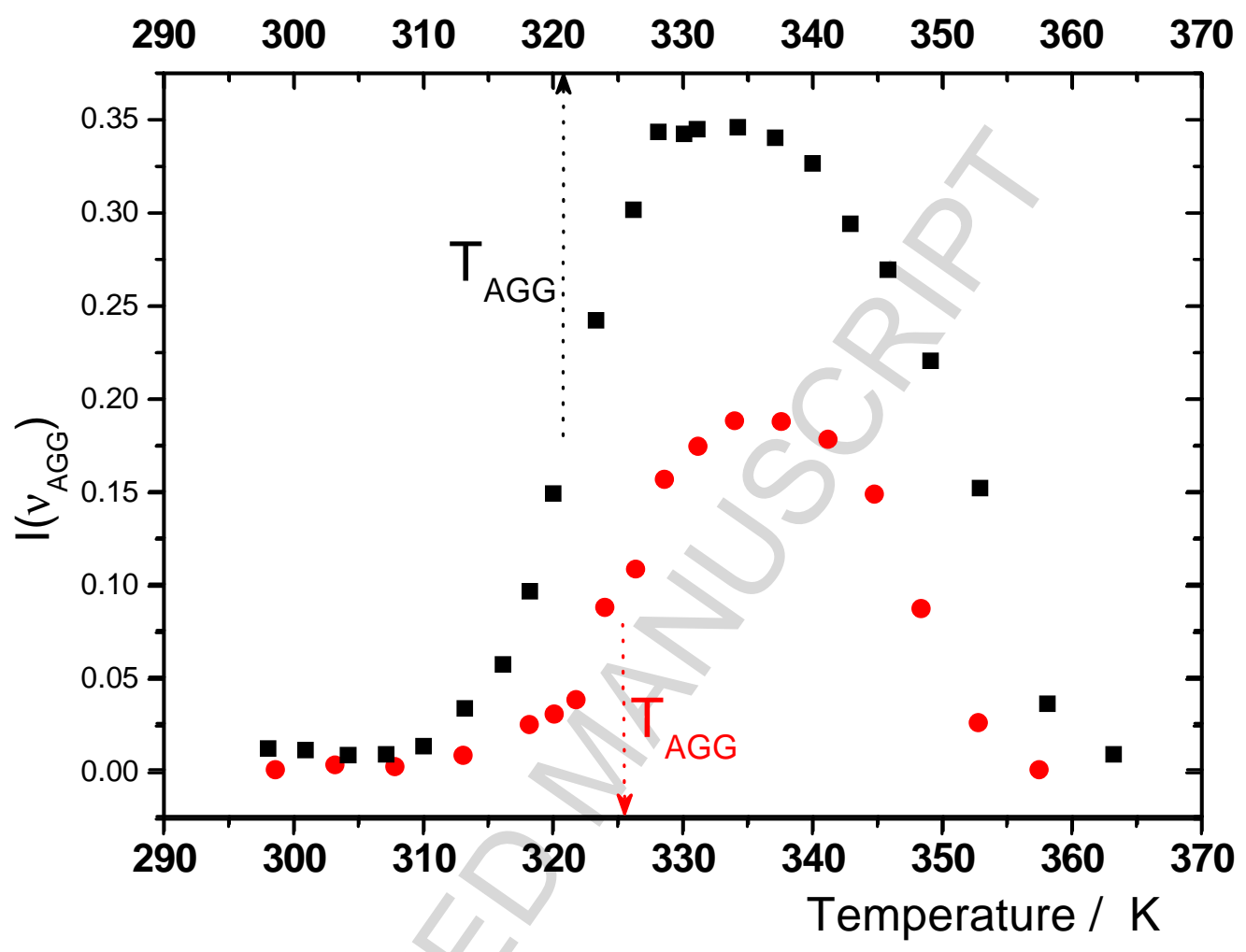

Figure 6 


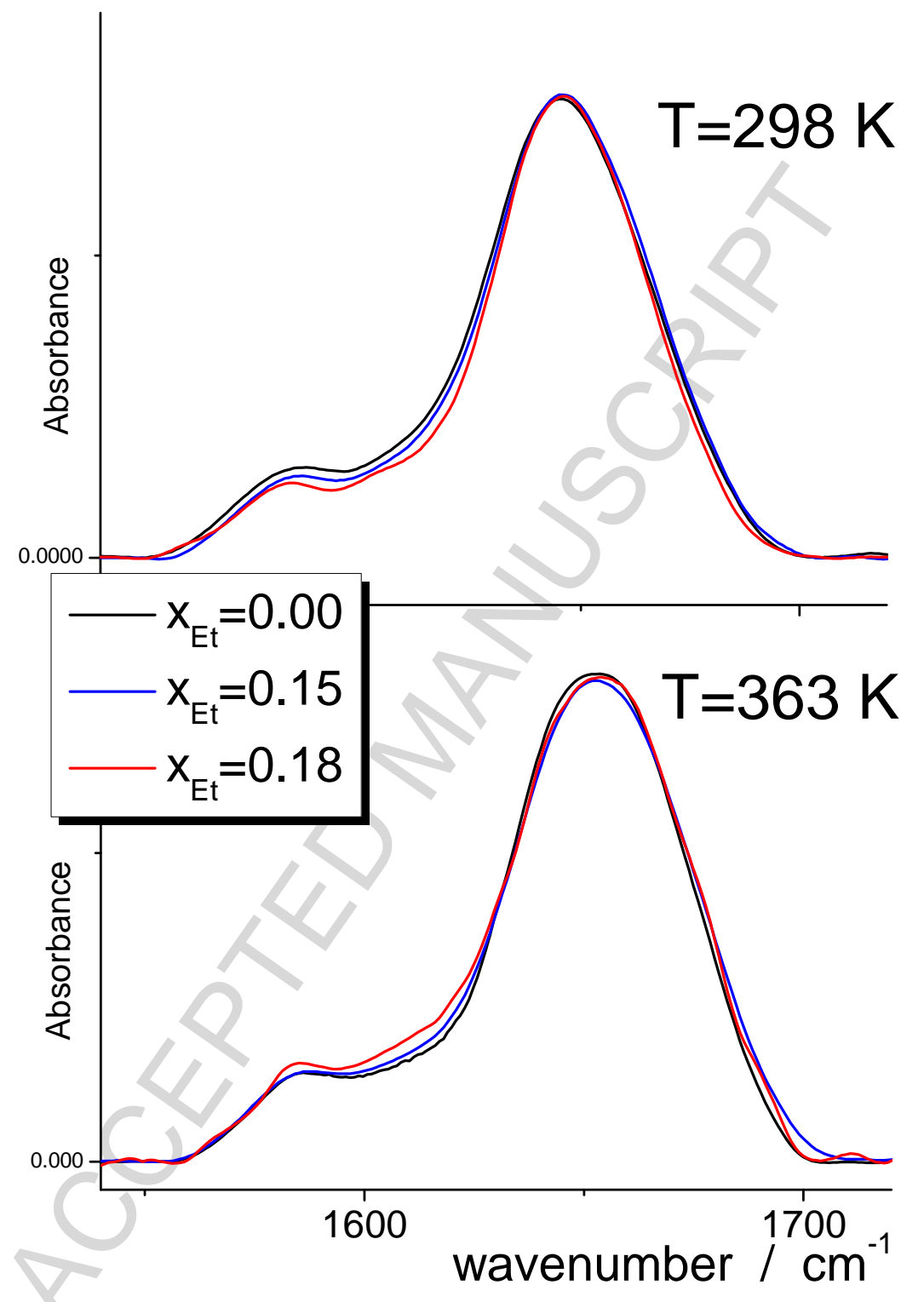

Figure 7 


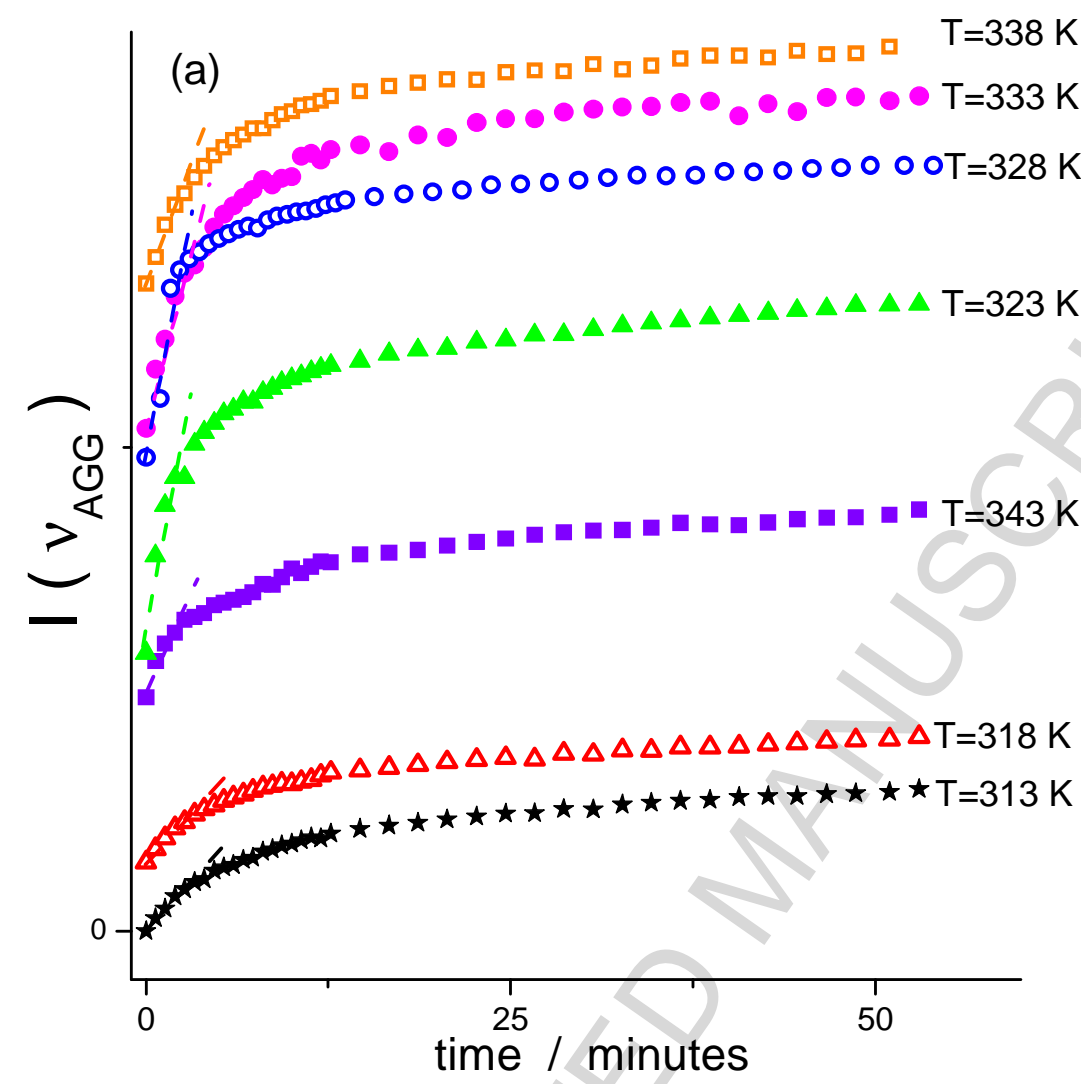

(b)

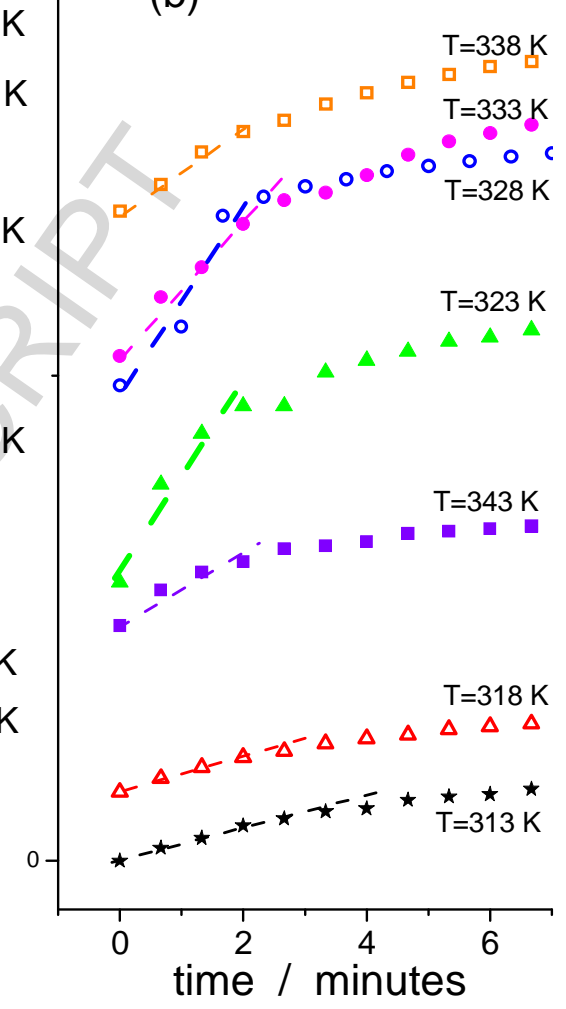

Figure 8 


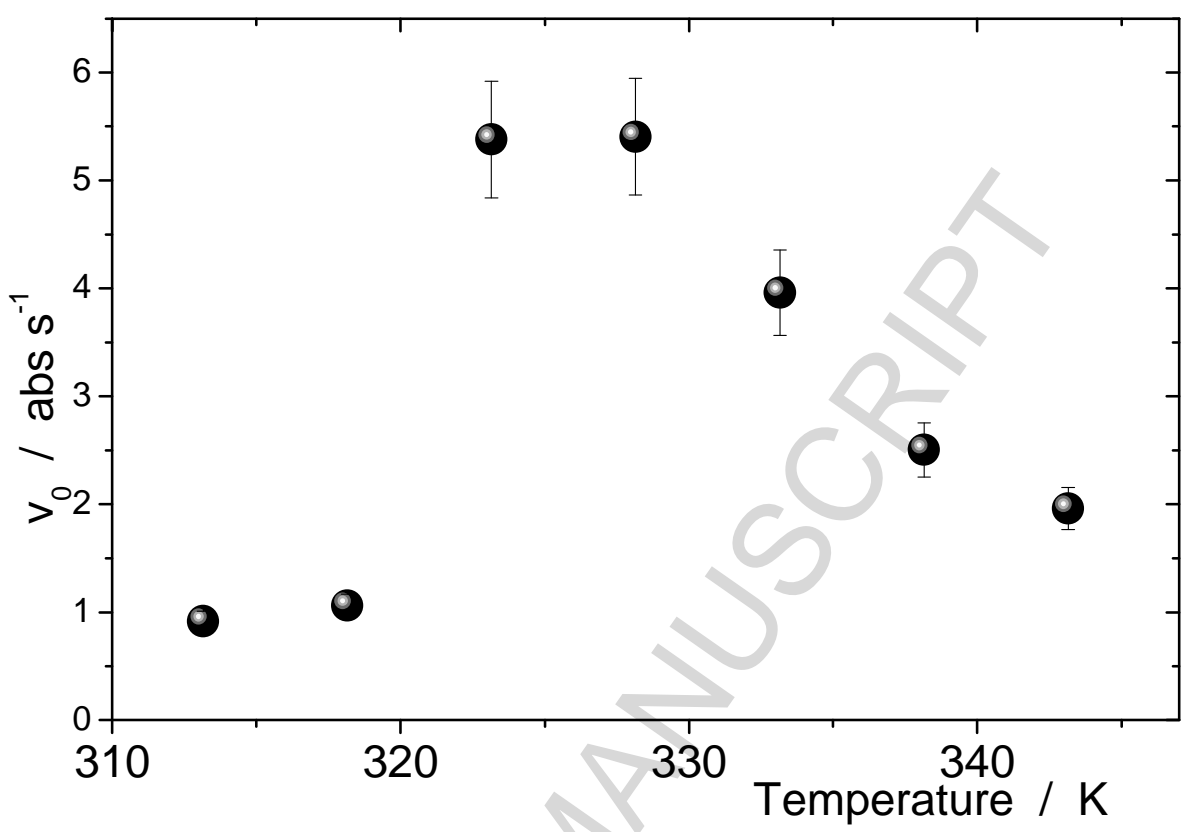

Figure 9 


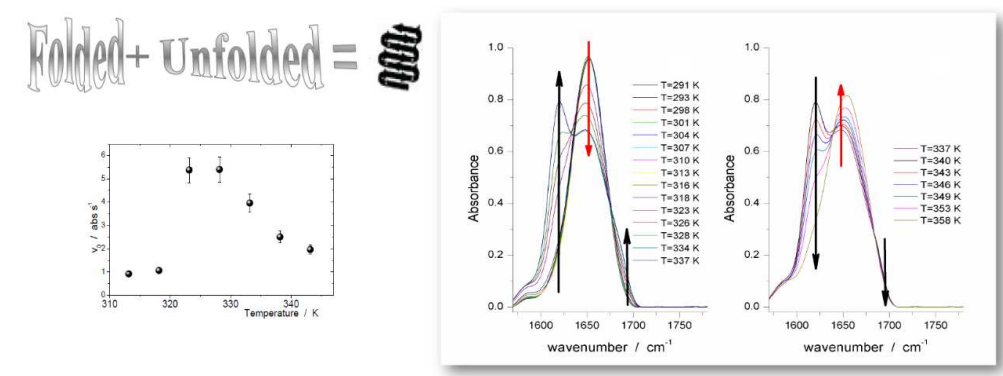

Graphical Abstract 


\section{Research Highlights -}

$>$ We followed the effects of ethanol addition to lysozyme/water solutions. > A reduced stability of the folded state was revealed on increasing ethanol fraction. > An enhancement of intermolecular interactions between protein chains was observed upon increase of alcohol concentration. > We evidenced an irreversible association initiated by the unfolded and the folded states of the macromolecule. $>$ We obtained different hydrogels under different thermal treatment of a single protein solution. 